UDC 159.99

LBC 88.53

\title{
SOCIOLOGICAL, PEDAGOGICALAND PSYCHOLOGICAL ASPECTS OF THE PROBLEM OF MONOLOGICALLY FAMILY: SCIENTIFIC REVIEW ${ }^{1}$
}

\author{
Irina V. Cheremisova \\ Volgograd State University, Volgograd, Russian Federation \\ Vladislav V. Serikov \\ Volgograd State University, Volgograd, Russian Federation
}

Olga V. Suvorova

Minin State Pedagogical University of Nizhny Novgorod, Nizhny Novgorod, Russian Federation

\begin{abstract}
The article presents the analysis of resent years' studies on the problems of single-parent families, lone parent, single mother. The results of the analysis of sociological, pedagogical and psychological studies carried out by Russian scientists have led to the conclusion about the acute relevance of this problem. Sociological research is aimed at studying the problems of the institutionalization of an incomplete family in a transforming society, the peculiarities of the life in a single-parent family, determining the types of families in modern society, the social status of a single-parent family, the personal and social problems of single mothers, the social status of single women mothers in the labor market. Finding a solution to the problem of socialization of children from single-parent families requires an interdisciplinary approach and is of interest of researchers in the framework of sociological, pedagogical and psychological science. From the standpoint of psychological and pedagogical science scientists study the external and internal determinants of the socialization process, age-related aspects of psychological and pedagogical support of socialization of children from single-parent families. Research on pedagogy is aimed at identifying the conditions for optimizing the interaction of a single parent with representatives of educational institutions, cultural institutions, public organizations. Teachers pay great attention to the development of programs to improve pedagogical literacy, pedagogical culture of single parents, practical recommendations to assist parents in the upbringing children, the organization of meaningful leisure of single-parent family members. In psychological research works the emphasis is placed on the peculiarities of emotional state, characteristics of educational potential, psychological conditions of activation of personal potential of a single mother. Attempts are made to describe the individual psychological characteristics of a single mother; to develop a typology of single mothers; to present the psychological structure of motherhood in an incomplete family; psychological characteristics of lifesituations in an incomplete ¿ family. The studies aimed at developing the methodological basis of psychological support programs for mother or father in $\curvearrowleft$ a single-parent family are of particular value and importance for psychological science and practice. The problems of single0 parent family, single mother are more reflected in sociological and pedagogical research. There is an acute shortage of work

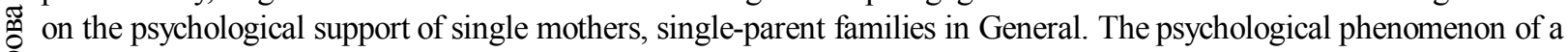
on single mother, her personal resources to solve the problems of an incomplete family have not yet been studied enough. S. Key words: single parent family, single mother, personal potential of mother, psychological support, culture, socialization of children.

УДК 159.99

ББК 88.53
\end{abstract}

\section{СОЦИОЛОГИЧЕСКИЙ, ПЕДАГОГИЧЕСКИЙ И ПСИХОЛОГИЧЕСКИЙ АСПЕКТЫ ПРОБЛЕМЫ МОНОРОДИТЕЛЬСКОЙ СЕМЬИ: НАУЧНЫЙ ОБЗОР ${ }^{1}$}

\author{
Ирина Валерьяновна Черемисова
}

Волгоградский государственный университет, г. Волгоград, Российская Федерация 


\section{Владислав Владиславович Сериков}

Волгоградский государственный университет, г. Волгоград, Российская Федерация

\section{Ольга Вениаминовна Суворова}

Нижегородский государственный педагогический университет им. Козьмы Минина, г. Нижний Новгород, Российская Федерация

Аннотация. В статье представлен анализ исследований последних лет по проблемам неполной семьи, одинокого родителя, одинокой матери. Результаты анализа социологических, педагогических и психологических исследований, выполненных отечественными учеными, позволили сделать вывод об острой актуальности данной проблемы. Социологические исследования направлены на изучение проблем институализации неполной семьи в трансформирующемся обществе, особенностей жизнедеятельности монородительской семьи, определение типов семей в современном обществе, социального статуса монородительской семьи, личностных и социальных проблем одиноких матерей, социального положения одиноких женщин-матерей на рынке труда. Поиск решения проблемы социализации детей из неполных семей требует междисциплинарного подхода и представляет интерес исследователей в рамках социологической, педагогической и психологической науки. С позиций психолого-педагогической науки ученые изучают внешние и внутренние детерминанты процесса социализации, возрастные аспекты психолого-педагогической поддержки социализации детей из неполных семей. Исследования по педагогике направлены на выявление условий оптимизации взаимодействия одинокого родителя с представителями образовательных учреждений, учреждений культуры, общественных организаций. Педагоги уделяют большое внимание разработке программ повышения педагогической грамотности, педагогической культуры одиноких родителей, практических рекомендаций для оказания помощи родителям в воспитании детей, организации содержательного досуга членов неполной семьи. В психологических трудах акцент ставится на особенностях эмоционального состояния, характеристике воспитательного потенциала, психологических условиях активизации личностного потенциала одинокой матери. Предпринимаются попытки описать индивидуально-психологические особенности одинокой матери; разработать типологию одиноких матерей; представить психологическую структуру материнства в неполной семье; психологическую характеристику жизненных ситуаций неполной семьи. Особую ценность и значимость для психологической науки и практики представляют исследования, направленные на разработку методологической основы программ психологического сопровождения матери или отца в монородительской семье. Проблемы монородительской семьи, одинокой матери в большей степени нашли отражение в социологических и педагогических исследованиях. Существует острый дефицит работ по проблемам психологического сопровождения одиноких матерей, неполной семьи в целом. Психологический феномен одинокой матери, ее личностные ресурсы для решения проблем неполной семьи пока исследованы недостаточно.

Ключевые слова: монородительская семья, одинокая мать, личностный потенциал матери, психологическое сопровождение, культура, социализация детей.

Анализ диссертационных исследований последних лет показал, что проблема монородительской семьи в России стоит достаточно остро. Социологические, педагогические, психологические, философские исследования разрабатывают различные аспекты проблемы монородительской семьи в целом и проблемы одинокой матери в частности.

Прежде всего обратим внимание на то, что ряд исследователей подчеркивают важность влияния культуры на развитие, на самоотношение и самочувствие личности [7-9; 12 ; 15; 17]. Эти выводы имеют особую значимость в контексте проблем монородительской семьи, одинокой женщины-матери. Канадский психолог П. Вайнцвайг в своей книге
«Десять заповедей творческой личности» рассказывает о возможностях формирования силы личности [2]. В его понимании сила личности - это в первую очередь любовь, творчество и мудрость. Это также свобода оставаться самим собой в самых различных ситуациях. Кроме того, П. Вайнцвайг подчеркивает, что культура обладает способностью просвещать, вдохновлять и укреплять человеческий характер. Знания в области культуры, утверждает П. Вайнцвайг, открывают бесконечные просторы мыслей и идей, активизируют воображение, порождают находчивость и укрепляют силу личности.

Социально-философский анализ типов семей в современном обществе представил в 
своей работе Н.Н. Николаев (2007). В работе Н.Н. Николаева предпринята попытка представить содержательный анализ динамики изменения типов семьи в период трансформации российского общества в конце $\mathrm{XX}$ в. на основе широкого спектра выделенных критериев. В целом автор исследования отмечает негативные тенденции, свидетельствующие о кризисе института семьи, появление большого разнообразия типов семей, обусловленного резкими социальными, политическими, экономическими изменениями в жизни современного российского общества. Н.Н. Николаев обращает особое внимание на типологию неблагополучных семей, типологию неполных семей, что имеет несомненную ценность для психолого-педагогической практики и социальной работы с семьей. Кроме того, Н.Н. Николаев в своей работе подчеркивает, что типология семьи усложняется за счет возникновения промежуточных типов семьи.

Проблемы неполных семей с учетом региональных особенностей изучали Е.С. Голосова (2010), О.А. Заякина (2003), Г.А. Кантемирова (2008), Г.З. Нафикова (2009); Б.Б. Нусхаева (2007).

Исследование Г.З. Нафиковой направлено на рассмотрение проблемы институализации неполной семьи, состоящей из детей и одного из родителей (чаще всего матери) в трансформирующемся обществе. На основе анализа результатов социологического исследования среди одиноких матерей в городах республики Башкортостан, Г.З. Нафикова выявила и описала основные тенденции развития семьи, свидетельствующие о снижении функциональной значимости семьи; определила традиционные и нетрадиционные источники воспроизводства неполных семей; установила, что уровень жизни неполных семей в условиях социально-экономических преобразований значительно снизился. Эти выводы исследователя представляются нам несколько сомнительными и стимулируют дискуссию, однако стоит признать значимость работы Г.З. Нафиковой для психолого-педагогической практики и социальной поддержки неполной семьи с учетом региональной специфики.

Особенности жизнедеятельности монородительской семьи рассматривала как социологическую проблему О.А. Заякина (2003).
Глубокий теоретический анализ отечественной и зарубежной философской, социологической, историко-социологической, социально-психологической и юридической литературы позволил О.А. Заякиной разработать стройную программу комплексного социологического исследования. Несомненную ценность работы О.А. Заякиной представляет выборка исследования, состоящая из многочисленных представителей неполных и полных семей разных регионов России, экспертов-работников социальных служб. Масштабное социологическое исследование позволило О.А. Заякиной определить содержание понятия «монородительская семья», выявить существенные признаки монородительской семьи с учетом региональной специфики (жители Урала), обогатить научное знание социологическими данными о жизнедеятельности монородительских семей, обосновать приоритетность монородительской семьи в качестве объекта социальной защиты.

Социологический анализ характеристик городской монородительской материнской семьи представила Л.К. Рашитова (2011). Интерес представляет выявленная и описанная Л.К. Рашитовой специфика проблем городской монородительской семьи в сравнении с монородительской семьей, проживающей в сельской местности. Кроме того, в работе Л.К. Рашитовой представлены новые источники формирования неполных семей (усыновление, использование методов искусственного оплодотворения). Ценным нам представляется изучение Л.К. Рашитовой важного аспекта проблем монородительской семьи, касающегося использования современных репродуктивных технологий (суррогатное материнство) одинокими женщинами и одинокими состоятельными мужчинами, желающими иметь ребенка. В связи с этим интересен вывод Л.К. Рашитовой о появлении совершенно нового типа современной монородительской семьи со специфическими социальными проблемами.

Анализ стратегий выживания монородительских семей в условиях малого города, социального статуса монородительской семьи в своей работе представила Е.А. Цыглакова (2005). Подчеркивая комплексный характер проблемы социального статуса монородительской семьи, Е.А. Цыглакова проводит срав- 
нительный анализ работ отечественных и зарубежных авторов в области социологии, истории, психологии, социальной работы. Важным, на наш взгляд, является то, что Е.А. Цыглакова акцентирует внимание на изучение гендерного аспекта данной проблемы, на необходимости учета специфики условий конкретного региона, малого города.

В исследовании материнства в качестве наиболее древнего и устойчивого социального института Л.Г. Сологуб (2001) подчеркивает, что особую тревогу вызывает значительное снижение воспитательного и социализирующего потенциала материнства в условиях современной России. Л.Г. Сологуб привлекает внимание к проблеме социальной незащищенности женщины-матери, описывает материнство в контексте социального риска. Вместе с тем Л.Г. Сологуб обозначила материнство как важнейшую форму самореализации женщины; современный кризис семьи и материнства как адаптационный процесс.

Личностные и социальные проблемы одиноких матерей исследовала Т.Н. Каменева (2003). Она описала социальную характеристику жизнедеятельности одиноких матерей; уточнила содержание основных понятий «внебрачное материнство», «одинокая мать», «семья одинокой матери»; обратила внимание на проблемы юных одиноких матерей, не имеющих достаточного образовательного, профессионального статуса.

Проблемы трудоустройства женщин с детьми и социальные аспекты женской безработицы на региональном рынке труда (Пензенская область) охарактеризовала Е.С. Голосова (2010). Анализ теоретических подходов к исследованию положения женщин в социально-трудовой сфере позволил Е.С. Голосовой выявить социальные аспекты проблемы женской безработицы с учетом быстро меняющихся социально-экономических условий в современной России. Интерес вызывает представленный в исследовании Е.С. Голосовой социальный портрет безработной женщины с ребенком, который содержит ее основные профессионально-трудовые характеристики, причины безработицы, способы поиска работы, особенности мотивации к обучению и переобучению. Тревожным фактором, отмеченным Е.С. Голосовой, является низкая мотивация в получении новой специальности, повышении квалификации женщин, имеющих детей. Особое внимание Е.С. Голосова привлекает к проблеме безработицы среди одиноких и многодетных матерей, воспитывающих детей дошкольного возраста и детей-инвалидов. Достоинством исследования Е.С. Голосовой считаем определение основных направлений работы для решения проблем женской безработицы, социально-трудовой адаптации женщин с детьми на региональном рынке труда.

Несомненный интерес в контексте проблем монородительской семьи, одинокого родителя представляет, на наш взгляд, докторская диссертация Ж.В. Пузановой «Социологическое измерение одиночества» (2009). Автор исследования подчеркивает междисциплинарность предмета изучения феномена одиночества и отмечает важность изучения данного феномена с позиций социологической науки. В своем исследовании проблемы одиночества Ж.В. Пузанова (2009) представила глубокий критический анализ различных методологических подходов к проблеме; разработала собственный методологический подход и методический инструментарий, позволивший исследовать феномен одиночества с позиций современной социологической науки; раскрыла понятие «одиночество» в его взаимосвязи с понятиями «уединение», «изоляция», «отчуждение»; исследовала «образ одинокого человека» в повседневном восприятии. Четкая, ясная логика исследования позволила Ж.В. Пузановой построить многокомпонентную модель феномена одиночества, в которую в качестве структурных элементов включены описательные объяснения одиночества (личностные смыслы), причинные объяснения и эмоциональная оценка.

Г.А. Кантемирова (2008), Б.Б. Нусхаева (2007) представили социологический аспект проблемы социализации детей в неполной семье.

Большинство исследований проблем неполной семьи с позиций психолого-педагогической науки обращено к условиям развития личности ребенка $[1 ; 3-6 ; 10 ; 11 ; 13 ; 14 ; 16]$.

Возрастные аспекты проблемы педагогической поддержки социализации детей из неполных семей изучали В.А. Барабохина (2013); Н.Н. Дружинина (2006); педагогические условия формирования конкурентоспособной лич- 
ности учащихся из неполных семей выявила и описала Е.А. Лапшина (2010); факторы формирования психологической готовности юношей к отцовству выявила и описала Н.А. Демчук (2006); содержание представлений женщин из неполных родительских семей, возникших в результате развода, вдовства и одинокого материнства, о лицах противоположного пола раскрыла Л.В. Аргентова (2007); особенности социально-психологической адаптации детей, воспитывающихся в семьях без отца, выявила и описала А.П. Кравченко (2011); внешние и внутренние детерминанты процесса социализации подростков из неполных семей с позиций психологической науки выявила В.А. Иванченко (2012).

В своей работе В.А. Иванченко отмечает, что эволюция семьи, ее структура и специфика отношений между всеми ее членами в психологических работах представлена единичными исследованиями. Очевидны некоторые общие тенденции, характеризующие состояние современной семьи: резкое уменьшение количества заключаемых браков, увеличение количества одиночек, снижение количества детей в семье. В.А. Иванченко предложила уточненную модель жизненного цикла неполной семьи, которая включает в себя следующие этапы: заключение брака, появление детей, распад семьи, адаптация к ситуации разрыва, принятие монородительства, взросление детей, сепарация детей, создание новой семьи.

В исследованиях по педагогике большое внимание уделяется взаимодействию одинокого родителя с представителями образовательных учреждений, учреждений культуры и социальной помощи, направленному на просвещение родителей, повышение их педагогической культуры, помощь в организации содержательного досуга и отдыха детей, семьи (Т.В. Бахуташвили (Коренькова), 2004; А.Б. Беляева, 2010; Г.Г. Воронцова, 2002; С.В. Зеленчукова, 2002; М.И. Кирикова (2009); Е.В. Неделина, 2002; Я.Г. Николаева, 2003; Т.И. Петрова, 2002 и др.).

Несомненный интерес вызывает исследование Е.Г. Якушенко клинико-психологических особенностей подростков разведенных родителей и одиноких разведенных матерей, расторгнувших брак более 7-10 лет назад. Срав- нение клинико-психологических особенностей одиноких разведенных матерей и матерей, состоящих в браке, позволило Е.Г. Якушенко условно разделить проблемы одиноких матерей после распада семьи на три вида: соматические, социальные, психологические. В качестве соматических проблем автор исследования выделяет проблемы функционирования нервной и опорно-двигательной систем организма. К социальным проблемам одинокой матери Е.Г. Якушенко относит неблагополучное материальное положение семьи, высокую занятость матери на работе и т. д. Среди психологических проблем одинокой женщины-матери автор исследования считает наиболее важной преобладание негативного эмоционального фона (страх будущего, чувство одиночества, обиды, вины). Эти проблемы, считает Е.Г. Якушенко, затрудняют адаптацию матерей после распада семьи, и это отрицательно сказывается на воспитательном потенциале одинокой матери.

Наиболее важным, на наш взгляд, в контексте нашего исследования является работа М.А. Мягковой (2013), направленная на изучение психологических особенностей материнства в неполной семье и разработку программы психологического сопровождения одинокой матери. В своем исследовании М.А. Мягкова проанализировала основные подходы к изучению материнства в зарубежной и отечественной психологии; выделила социально-психологические условия, способствующие формированию неполных семей; разработала и представила психологическую структуру материнства в полной и неполной семье; разработала типологию одиноких и не одиноких матерей, разработала и проверила результативность программы психологического сопровождения материнства в неполной семье. В структуре материнства М.А. Мягкова выделила три компонента - когнитивный, эмоциональный и поведенческий. Индивидуально-психологические особенности материнства в неполной семье, по мнению автора исследования, определяются взаимодействием трех факторов, соответствующих структурно-содержательным компонентам материнства: представление о материнстве, материнские чувства, материнское поведение. Психологическое сопровождение материнства М.А. Мягкова предла- 
гает осуществлять посредством воздействия на мать через структурные компоненты материнства в диагностической, информационной, консультативной и тренинговой работе. Анализ результатов исследования позволил М.А. Мягковой сделать вывод, что материнство в неполной семье - феномен, проявляющийся в изменении его содержания. Это проявляется в снижении степени осознанности материнских позиций и установок, негативном отношении к отцу ребенка, снижении степени проявления материнской любви, высоком уровне устойчивости поведения, снижении степени ответственности и осознанности воспитания. Некоторые выводы М.А. Мягковой стимулируют вопросы для дискуссии, вызывают несогласие: не совсем понятны критерии типологии одиноких и не одиноких матерей, логика этапов программы психологического сопровождения (диагностический, информационный, тренинговый, консультативный). Вместе с тем работа М.А. Мягковой представляет несомненную ценность и значимость для психологической науки и практики, поскольку в ней предпринята попытка восполнить острый дефицит психологических исследований проблемы разработки методологических основ и создания программ психологического сопровождения одинокой матери.

Таким образом, анализ социологических, педагогических, психологических исследований последних лет показал, что проблемы монородительской семьи, одинокого родителя в большей степени нашли отражение в социологических и педагогических трудах. Приходится констатировать острый дефицит психологических исследований феномена монородительской семьи.

В перспективе психологические исследования могут быть обращены к различным уровням решения проблем монородительской семьи: парадигмальному (разработка философско-психологических основ); общенаучному (отбор психологического инструментария для исследования обозначенной проблемы); теоретическому (интерпретация социальнопсихологических тенденций и особенностей материнства в неполной семье) и технологическому (разработка программ психологического сопровождения материнства в неполной семье). Это позволит расширить представле- ния о специфике функционирования монородительской семьи, возможностях социальной и психолого-педагогической помощи семье и особенностях психологического сопровождения развития личности члена семьи, гармонизации межличностных отношений в семье.

\section{ПРИМЕЧАНИЕ}

${ }^{1}$ Статья подготовлена в рамках НОЦ «Психология: наука и практика».

\section{СПИСОК ЛИТЕРАТУРЫ}

1. Бурменская, Г. В. Привязанность ребенка к матери и особенности его самооценки / Г. В. Бурменская, И. А. Борисова, Е. В. Пупырева // Психологические проблемы современной российской семьи : материалы Всерос. науч. конф. (г. Москва, 14-16 окт. 2003 г.). Ч. 1. - М., 2003. - С. 202-207.

2. Вайнцвайг, П. Десять заповедей творческой личности / П. Вайнцвайг ; пер. с англ. С. Л. Лойко и Ф. Б. Сарнова. - М. : Прогресс, 1990. - 221 с.

3. Васильева, Е. Н. Эмоциональное и социальное развитие старшего дошкольника в зависимости от материнского принятия / Е. Н. Васильева, О. В. Суворова // Вестник Нижегородского университета им. Н.И. Лобачевского. Серия: Социальные науки. - 2004. - № 1. - С. 13-26.

4. Воробьева, Е. В. Влияние ретроспективной оценки материнского стиля воспитания, реализуемого в детстве, на проявления алекситимии и эмпатии у молодежи с полинаркоманией / Е. В. Воробьева, И. П. Шульгина, П. Н. Ермаков // Российский психологический журнал. - 2015. - Т. 12, № 3. C. 114-133.

5. Захарова, Е. И. Исследование особенностей эмоциональной стороны детско-родительского взаимодействия / Е. И. Захарова // Психолог в детском саду. - 1998. - № 1. - С. 9-17.

6. Захарова, Е. И. Диагностика характера детско-родительских отношений в пробе на совместную деятельность / Е. И. Захарова, О. А. Карабанова // Психолог в детском саду. - 2002. - № 1. C. $41-60$.

7. Калашникова, Н. А. Критическое мышление, логическая культура личности и модели возможного мира / Н. А. Калашникова, С. Б. Токарева // Вестник Волгоградского государственного университета. Серия 7, Философия. Социология, социальные технологии. - 2016. - № 4 (34). - С. 183-187.

8. Курышева, И. В. Психологические основы музыкально-творческого развития личности в образовательном процессе : дис. ... д-ра психол. наук : 
19.00.07 / Курышева Ирина Валерьяновна. - Н. Новгород, 2011. $-438 \mathrm{c}$.

9. Люсова, О. В. Жизненное проектирование студентов вуза как средство самореализации в настоящем / О. В. Люсова, Е. М. Глухова // Современные проблемы науки и образования. - 2017. - № 5. Электрон. текстовые дан. - Режим доступа: http: //www.science-education.ru/article/view?id=26784 (дата обращения: 19.09.2017). - Загл. с экрана.

10. Суворова, О. В. Влияние эмоционального взаимодействия матери на самоотношение старшего дошкольника / О. В. Суворова, И. В. Черемисова, Е. Б. Мамонова // Вестник Мининского университета. - 2017. - № 1 (18). - Электрон. текстовые дан. Режим доступа: http://vestnik.mininuniver.ru. - Загл. с экрана.

11. Суворова, О. В. Привязанность к матери как фактор Я-концепции подростка / О. В. Суворова, И. В. Черемисова, Е. Б. Мамонова // Вестник Мининского университета. - 2016. - № 2 (15). С. 36. - Электрон. текстовые дан. - Режим доступа: http://vestnik.mininuniver.ru. - Загл. с экрана.

12. Терелянская, И. В. Психологические подходы к понятию конкурентоспособности личности / И. В. Терелянская, И. В. Курышева // Мир науки, культуры, образования. - 2012. - № 2 (33). C. $236-238$.

13. Терентьев, А. В. Влияние эмоционально зависимых отношений на формирование готовности к семейной жизни будущих спортсменов / А. В. Терентьев, И. В. Черемисова // Физическое воспитание и спортивная тренировка. - 2015. - № 5 (11). C. $96-98$.

14. Черемисова, И. В. Вторичная музыкальная личность: психологические условия развития на этапе поздней взрослости / И. В. Черемисова // Горизонты зрелости : сб. тез. участников Пятой всерос. науч.-практ. конф. по психологии развития. М . : ГБОУ ВПО МГППУ, 2015. - С. 599-603.

15. Черемисова, И. В. Вторичная музыкальная личность: философско-культурологические основы исследования и развития / И. В. Черемисова // Вестник Волгоградского государственного университета. Серия 7, Философия. Социология и социальные технологии. - 2016. - № 3 (33). - С. 95-101.

16. Черемисова, И. В. Противодействие депривации личности с позиции эстетико-семиотического подхода / И. В. Черемисова // Личностная депривация: юридический, психологический, междисциплинарный аспекты : коллектив. моногр. / отв. ред. В. М. Мелихов, О. Н. Макаренко, Г. Г. Егоров. Волгоград : Царицынская полиграфическая компания, 2014. - С. 196-219.

17. Cheremisova, I. V. Music and Development of Creative Personality Within Higher Education Environment. Aesthetic and Semiotic Approach
/ I. V. Cheremisova//European Journal ofMultidisciplinary Studies. -2017. - Vol. 4, № 1.-P. 78-87. -DOI: 10.26417/ ejms.v4i1.p78-87.

\section{REFERENCES}

1. Burmenskaya G.V., Borisova I.A., Pupyreva E.V. Privyazannost rebenka k materi i osobennosti ego samootsenki [The Child's Attachment to Their Mother and Peculiarities of Their Self-Esteem]. Psikhologicheskie problemy sovremennoy rossiyskoy semyi: materialy Vseros. nauch. konf. (g. Moskva, 1416 okt. 2003 g.). Ch. 1 [Psychological Problems of Modern Russian Family: Proceedings of the AllRussian Academic Conference (Moscow, October 1416, 2003). Part 1]. Moscow, 2003, pp. 202-207.

2. Vayntsvayg P. Desyat zapovedey tvorcheskoy lichnosti [Ten Commandments of the Creative Personality]. Moscow, Progress Publ., 1990. 221 p.

3. Vasilyeva E.N., Suvorova O.V. Emotsionalnoe i sotsialnoe razvitie starshego doshkolnika $\mathrm{v}$ zavisimosti ot materinskogo prinyatiya [Emotional and Social Development of the Senior Preschooler, Depending on the Mother's Acceptance]. Vestnik Nizhegorodskogo universiteta im. N.I. Lobachevskogo. Seriya: Sotsialnye nauki, 2004, no. 1, pp. 13-26.

4. Vorobyeva E.V., Shulgina I.P., Ermakov P.N. Vliyanie retrospektivnoy otsenki materinskogo stilya vospitaniya, realizuemogo $\mathrm{v}$ detstve, na proyavleniya aleksitimii i empatii u molodezhi s polinarkomaniey [Influence of a Retrospective Evaluation of the Maternal Style of Upbringing Realized in Childhood, on Manifestations of Alexithymia and Empathy in Young People With Polydrug Use]. Rossiyskiy psikhologicheskiy zhurnal, 2015, vol. 12, no. 3, pp. 114-133.

5. Zakharova E.I. Issledovanie osobennostey emotsionalnoy storony detsko-roditelskogo vzaimodeystviya [Investigation of the Emotional Aspect of the Child-Parent Interaction]. Psikholog v detskom sadu, 1998, no. 1, pp. 9-17.

6. Zakharova E.I., Karabanova O.A. Diagnostika kharaktera detsko-roditelskikh otnosheniy v probe na sovmestnuyu deyatelnost [Diagnostics of the Nature of Child-Parent Relations in a Trial for Joint Activity]. Psikholog v detskom sadu, 2002, no. 1, pp. 41-60.

7. Kalashnikova N.A., Tokareva S.B. Kriticheskoe myshlenie, logicheskaya kultura lichnosti i modeli vozmozhnogo mira [Critical Thinking, Logical Culture of Personality and Models of a Possible World]. Vestnik Volgogradskogo gosudarstvennogo universiteta. Seriya 7, Filosofiya. Sotsiologiya, sotsialnye tekhnologii [Science Journal of Volgograd State University. Philosophy. Sociology and Social Technologies], 2016, no. 4 (34), pp.183-187. 
8. Kurysheva I.V. Psikhologicheskie osnovy muzykalno-tvorcheskogo razvitiya lichnosti $v$ obrazovatelnom protsesse: dis. ... d-ra psikhol. nauk [Psychological Foundations of the Musical and Creative Development of the Individual in the Educational Process. Dr. psychol. sci. abs. diss.]. Nizhny Novgorod, 2011. 438 p.

9. Lyusova O.V., Glukhova E.M. Zhiznennoe proektirovanie studentov vuza kak sredstvo samorealizatsii v nastoyashchem [Life Designing of University Students as a Means of Self-Realization in the Present]. Sovremennye problemy nauki $i$ obrazovaniya, 2017, no. 5. URL: http://www.scienceeducation.ru/article/view?id=26784. (accessed September 19, 2017).

10. Suvorova O.V., Cheremisova I.V., Mamonova E.B. Vliyanie emotsionalnogo vzaimodeystviya materi na samootnoshenie starshego doshkolnika [Influence of the Mother's Emotional Interaction on the SelfAttitude of the Senior Preschooler]. Vestnik Mininskogo universiteta, 2017, no. 1 (18). URL: http: //vestnik.mininuniver.ru.

11. Suvorova O.V., Cheremisova I.V., Mamonova E.B. Privyazannost k materi kak faktor Yakontseptsii podrostka [Attachment to the Mother as a Factor of the Teenager's Self-Concept]. Vestnik Mininskogo universiteta, 2016, no. 2(15), p. 36. URL: $\mathrm{http} / / /$ vestnik.mininuniver.ru.

12. Terelyanskaya I.V., Kurysheva I.V. Psikhologicheskie podkhody $\mathrm{k}$ ponyatiyu konkurentosposobnosti lichnosti [Psychological Approaches to the Concept of Personality Competitiveness]. Mir nauki, kultury, obrazovaniya, 2012, no. 2 (33), pp. 236-238.

13. Terentyev A.V., Cheremisova I.V. Vliyanie emotsionalno zavisimykh otnosheniy na formirovanie gotovnosti k semeynoy zhizni budushchikh sportsmenov [The Influence of Emotionally
Dependent Relationships on the Formation of Readiness for the Family Life of Future Sportsmen]. Fizicheskoye vospitanie i sportivnaya trenirovka, 2015, no. 5 (11), pp. 96-98.

14. Cheremisova I.V. Vtorichnaya muzykalnaya lichnost: psikhologicheskie usloviya razvitiya na etape pozdney vzroslosti [Secondary Musical Personality: Psychological Conditions of Development at the Stage of Late Adulthood]. Gorizonty zrelosti: sb. tez. uchastnikov Pyatoy vseros. nauch.-prakt. konf. po psikhologii razvitiya [Horizons of Maturity. The Collection of Theses of Participants of the Fifth All-Russian Scientific-Practical Conference on Developmental Psychology]. Moscow, GBOU VPO MGPPU Publ., 2015, pp. 599-603.

15. Cheremisova I.V. Vtorichnaya muzykalnaya lichnost: filosofsko-kulturologicheskie osnovy issledovaniya i razvitiya [Secondary Musical Personality: Philosophical and Cultural Bases of Research and Development]. Vestnik Volgogradskogo gosudarstvennogo universiteta. Seriya 7, Filosofiya. Sotsiologiya, sotsialnye tekhnologii [Science Journal of Volgograd State University. Philosophy. Sociology and Social Technologies], 2016, no. 3 (33), pp. 95-101.

16. Cheremisova I.V. Protivodeystvie deprivatsii lichnosti s pozitsii estetiko-semioticheskogo podkhoda [Counteraction to Person's Deprivation (Aesthetic-Semiotic Approach)]. Lichnostnaya deprivatsiya: yuridicheskiy, psikhologicheskiy, mezhdistsiplinarnyy aspekty [Personal Deprivation: Legal, Psychological, Interdisciplinary Aspects]. Volgograd, Tsaritsynskaya poligraficheskaya kompaniya Publ., 2014, pp. 196-219.

17. Cheremisova I.V. Music and Development of Creative Personality Within Higher Education Environment. Aesthetic and Semiotic Approach. European Journal of Multidisciplinary Studies, 2017, vol. 4, no. 1, pp. 78-87. DOI: 10.26417/ejms.v4i1.p78-87.

\section{Information about the Authors}

Irina V. Cheremisova, Doctor of Psychological Sciences, Associate Professor, Head of Department of Psychology, Volgograd State University, Prosp. Universitetsky, 100, 400062 Volgograd, Russian Federation, cheremisova@volsu.ru.

Vladislav V. Serikov, Doctor of Pedagogical Sciences, Corresponding Member of the Russian Academy of Education, Professor, Department of Psychology, Volgograd State University, Prosp. Universitetsky, 100, 400062 Volgograd, Russian Federation, serikov@volsu.ru.

Olga V. Suvorova, Doctor of Psychological Sciences, Professor, Department of Classical and Applied Psychology, Minin State Pedagogical University of Nizhny Novgorod, Ulyanova St., 1, 604950 Nizhny Novgorod, Russian Federation, olgavenn@yandex.ru. 


\section{Информация об авторах}

Ирина Валерьяновна Черемисова, доктор психологических наук, доцент, заведующая кафедрой психологии, Волгоградский государственный университет, просп. Университетский, 100, 400062 г. Волгоград, Российская Федерация, cheremisova@volsu.ru.

Владислав Владиславович Сериков, доктор педагогических наук, член-корреспондент PAO, профессор кафедры психологии, Волгоградский государственный университет, просп. Университетский, 100, 400062 г. Волгоград, Российская Федерация, serikov@volsu.ru.

Ольга Вениаминовна Суворова, доктор психологических наук, профессор кафедры классической и практической психологии, Нижегородский государственный педагогический университет им. К. Минина, ул. Ульянова, 1, 604950 г. Нижний Новгород, Российская Федерация, olgavenn@yandex.ru. 